\title{
Highly Transparent, Flexible, and Thermally Stable Superhydrophobic ORMOSIL Aerogel Thin Films
}

\author{
Hulya Budunoglu, ${ }^{\dagger}$ Adem Yildirim, ${ }^{\dagger}$ Mustafa O. Guler, ${ }^{\dagger}$ and Mehmet Bayindir ${ }^{*,+,}$ \\ ${ }^{\dagger}$ UNAM-Institute of Materials Science and Nanotechnology, Bilkent University, 06800 Ankara, Turkey, and \\ ${ }^{\ddagger}$ Department of Physics, Bilkent University, 06800 Ankara, Turkey \\ Supporting Information
}

ABSTRACT: We report preparation of highly transparent, flexible, and thermally stable superhydrophobic organically modified silica (ORMOSIL) aerogel thin films from colloidal dispersions at ambient conditions. The prepared dispersions are suitable for large area processing with ease of coating and being directly applicable without requiring any pre- or posttreatment on a variety of surfaces including glass, wood, and plastics. ORMOSIL films exhibit and retain superhydrophobic
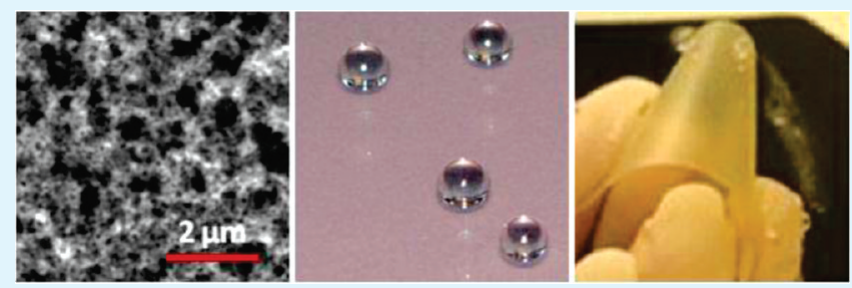

behavior up to $500{ }^{\circ} \mathrm{C}$ and even on bent flexible substrates. The surface of the films can be converted from superhydrophobic (contact angle of $179.9^{\circ}$ ) to superhydrophilic (contact angle of $<5^{\circ}$ ) by calcination at high temperatures. The wettability of the coatings can be changed by tuning the calcination temperature and duration. The prepared films also exhibit low refractive index and high porosity making them suitable as multifunctional coatings for many application fields including solar cells, flexible electronics, and lab on papers.

KEYWORDS: Aerogel, ORMOSIL thin film, superhydrophobic surface, porous materials, low refractive indices, optical transparency, flexible substrate, ambient pressure drying

\section{INTRODUCTION}

Superhydrophobic surfaces with water contact angle (CA) larger than $150^{\circ}$ and a sliding angle (SA) lower than $10^{\circ}$ have potential applications including self-cleaning materials, stainresistant textiles, and prevention of snow accumulation on outdoor antennas and windows. ${ }^{1,2}$ Self-cleaning Lotus leaf is a wellknown superhydrophobic surface in nature which is composed of micrometer- and nanometer-scaled patches coated with a $1 \mathrm{~nm}$ thick hydrophobic layer. The roughness of the patches enables trapping of air below the water droplet, thus helping the rolling of water droplets easily, resulting in a well designed superhydrophobic surface. ${ }^{3}$ Inspired by this structure, many artificial superhydrophobic surfaces have been produced, with a variety of techniques such as sol-gel techniques, ${ }^{4-7}$ co-condensation, ${ }^{8,9}$ layer-by-layer deposition, ${ }^{10,11}$ hydrothermal synthesis, ${ }^{12,13}$ electrospinning, ${ }^{14,15}$ chemical deposition, ${ }^{16}$ and lithographic methods. ${ }^{17-19}$ However, simple, low-cost, and large area fabrication of superhydrophobic surfaces, which is crucial for practical applications, is rarely achieved. In addition, durability and transparency of superhydrophobic surfaces are also important for many applications.

Here, we report a simple, large area, inexpensive sol-gel method to produce highly transparent and flexible organically modified silica (ORMOSIL) superhydrophobic aerogel thin films with good thermal and mechanical stability. ORMOSIL materials are preferred due to their unique properties between those of polymers and glasses meeting the requirements, such as flexibility and stability at atmospheric conditions, which cannot be afforded by either organic polymers or glasses alone. In addition, it is possible to change both chemical and physical properties of the resulting surfaces, such as wettability, by changing the organic group on the ORMOSIL. ${ }^{20}$ To date, some superhydrophobic ORMOSIL surfaces have been produced with electrospinning, co-condensation, and vapor deposition methods starting with alkyl-functional precursors such as methyltrimethoxysilane (MTMS) and trichloromethylsilane (TCMS). ${ }^{9,21-24}$ However, some of these coatings are not transparent, ${ }^{21,24}$ some need preand post-treatment, ${ }^{23}$ and some do not have good control over thickness and porosity. 9,22 On the other hand, ORMOSIL aerogel thin films produced in this work are highly transparent, do not need any pre or post surface treatments and can be applied on a variety of substrates including glass, wood, and plastics at ambient conditions with common thin-film deposition methods such as spin, dip, and spray coating. Also, the films on flexible substrates exhibited superhydrophobic behavior after bending multiple times. Furthermore, films preserved superhydrophobic behavior up to $500{ }^{\circ} \mathrm{C}$, and above $600{ }^{\circ} \mathrm{C}$ the films became superhydrophilic $\left(\right.$ contact angle $\left.<5^{\circ}\right){ }^{25}$

Received: November 15, 2010

Accepted: December 21, 2010

Published: January 12, 2011 
Table 1. Compositions, Annealing Conditions, Porosity, Refractive Indices, Average Roughness Values, and Contact Angles of Aerogel Thin Films

\begin{tabular}{|c|c|c|c|c|c|c|}
\hline sample & MeOH:MTMS fraction & annealing $\left({ }^{\circ} \mathrm{C}\right)$ & porosity (\%) & refractive index ${ }^{a}$ & roughness $(\mathrm{nm})$ & contact angle (deg) \\
\hline Me15-a & $15: 1$ & & 60 & 1.16 & 43 & $142.5 \pm 1.0$ \\
\hline Me15-b & $15: 1$ & 450 & 78 & 1.09 & 51 & $170.4 \pm 4.3$ \\
\hline Me25-a & $25: 1$ & & 60 & 1.16 & 43 & $171.1 \pm 2.0$ \\
\hline $\mathrm{Me} 25-\mathrm{b}$ & $25: 1$ & 450 & 78 & 1.09 & 40 & $164.8 \pm 3.2$ \\
\hline Me35-a & $35: 1$ & & 75 & 1.10 & 120 & $178.4 \pm 1.5$ \\
\hline Me35-b & $35: 1$ & 450 & 75 & 1.08 & 86 & $179.5 \pm 0.4$ \\
\hline Me35-c & $35: 1$ & 600 & 88 & 1.05 & 67 & $<5$ \\
\hline
\end{tabular}

Superhydrophobic ORMOSIL aerogel thin films were produced from colloidal dispersions obtained by breaking ORMOSIL gels into small pieces with sonication. The ORMOSIL gels were synthesized by using only methyltrimethoxysilane (MTMS) precursor. First, MTMS hydrolyzes under acidic conditions and then condenses to form a gel network under basic conditions. The resulting gel is opaque due to macroscopic phase separation during gelation, induced by MTMS monomer forming cyclic and cage-like closed species; ${ }^{26-28}$ however, the resulting thin films are highly transparent. The surface of thin films is covered with nonhydrolyzable methyl groups. They prevent collapse of the pores inside the gel during solvent evaporation (spring-back effect) ${ }^{29-31}$ at ambient temperature and pressure and result in a highly porous structure with hydrophobic surface groups. ${ }^{30,32-34}$ Also, covalently bonded organic methyl groups provide formation of a flexible network by decreasing the number of inorganic ( $\mathrm{Si}-\mathrm{O}-\mathrm{Si}$ ) bonds (less cross-linked). Thus, by using only MTMS as monomer it is possible to obtain flexible and intrinsically superhydrophobic aerogel structures in a single step.

\section{EXPERIMENTAL SECTION}

MTMS, methanol, oxalic acid, and ammonium hydroxide (26\%) were purchased from Sigma-Aldrich (U.S.) and used as purchased. Gels were obtained by two-step acid-base catalysis mechanism. ${ }^{30}$ In the first step of the preparation for $35 \mathrm{~mol}$ fraction methanol-containing gels, $1 \mathrm{~mL}$ of MTMS was dissolved in $9.74 \mathrm{~mL}$ of methanol. Following the addition of $0.5 \mathrm{~mL}$ of $0.001 \mathrm{M}$ oxalic acid solution the reaction mixture was stirred for $30 \mathrm{~min}$ and left for hydrolysis for $24 \mathrm{~h}$ at room temperature. After the hydrolysis, $0.61 \mathrm{~mL}$ of $11.2 \mathrm{M}$ ammonium hydroxide solution was dropwise added to the reaction mixture in order to catalyze the condensation reaction. Following $15 \mathrm{~min}$ of stirring, the solution was left for gelation and aging for $2 \mathrm{~d}$ at room temperature. The resulting gel was diluted with $10 \mathrm{~mL}$ of methanol and homogenized, by using an ultrasonic liquid homogenizer, ${ }^{29}$ for $45 \mathrm{~s}$ at $20 \mathrm{~W}$ power. The obtained homogenized solution was spin-coated at a rate of $2000 \mathrm{rpm}$ on glass microscope slides which were cleaned in an ultrasonic cleaner for $15 \mathrm{~min}$ with ethanol. Prepared ORMOSIL films were left to dry at room temperature overnight for complete evaporation of remaining solvent. The films were named with the first number in the abbreviation (Me35-a) indicating the mol fraction of methanol and the letter following the dash indicating the heat treatment condition, where "a" is used for asprepared films, and "b" and "c" are used for the films annealed at 450 and $600{ }^{\circ} \mathrm{C}$ for $1 \mathrm{~h}$, respectively. A contact angle meter (OCA 30, Dataphysics) was used to measure the static water contact angles on the ORMOSIL aerogel thin films before and after annealing steps. Water droplets of $0.4 \mu \mathrm{L}$ volume were used with Laplace-Young fitting for contact angle measurements. Microstructure observations of thin films were carried out using an environmental scanning electron microscope
(E-SEM, Quanta 200F, FEI) at low vacuum conditions. Nanostructure of the ORMOSIL aerogel structure was visualized by bright-field images with a transmission electron microscope (TEM, Tecnai G2 F30, FEI) operated at $200 \mathrm{kV}$. The TEM samples were prepared on holey carbon coated copper grid by scratching a piece from the films into a drop of ethanol and placing it on the grid. Surface roughness was analyzed using an atomic force microscope (AFM, XE-100E, PSIA) at noncontact mode. Spectroscopic refractive index measurements were obtained by an Ellipsometer (V-Vase, J. A. Woollam). Optical transmission measurements were carried out using a UV-vis spectrophotometer (Carry 100 Bio, Varian). Chemical analysis of the surface was performed using X-ray photoelectron spectroscopy (XPS, K-Alpha, Thermo Scientific). Detailed chemical analyses were performed using thermal gravimetric analysis (TGA, Q500, TA Instruments) and differential scanning calorimetry (DSC, Q2000, TA Instruments). Functional groups were characterized by using a Fourier transform infrared spectrometer (FTIR, Vertex 70, Bruker).

\section{RESULTS AND DISCUSSION}

Highly transparent and superhydrophobic ORMOSIL aerogel thin films were prepared from three different gels with varying molar ratios of MTMS, methanol, and water (1:35:8, 1:25:8, and 1:15:8 respectively, given in Table 1$)$. Gels were prepared in two steps: acid-catalyzed hydrolysis and base-catalyzed condensation. Prepared gels were aged for $2 \mathrm{~d}$ at room temperature in order to strengthen the gel network and to prevent pore collapse during ambient drying. We observed pore collapse and nonhomogeneous film formation for gels aged for shorter periods. Following the aging, they were diluted with methanol and sonicated to break down the gel network in order to form a homogeneous suspension. The prepared suspensions were stable up to $24 \mathrm{~h}$ depending on the amount of methanol added during dilution, and they can be resuspended with sonication. The ORMOSIL suspension can be easily applied on various surfaces with common coating techniques such as spin, dip, and spray coating. Furthermore, the films exhibit superhydrophobic property immediately after coating without requiring any posttreatments.

The surface morphologies of ORMOSIL aerogel films were investigated by SEM analysis given in Figure 1. SEM images indicated that all the films had highly porous networks, and as the mol fraction of methanol increased the films tended to have a structure with larger pores. A denser film was observed for Me15-a (Figure 1a) whereas Me25-a and Me35-a (Figure $1 \mathrm{~b}$ and c) revealed more of the micrometer-sized holes. The contact angle of a surface is related both with surface energy and the roughness. ${ }^{35,36}$ Produced aerogel thin films contain both micrometerand nanometer-scale roughness similar to lotus leaves., ${ }^{3,37}$ 

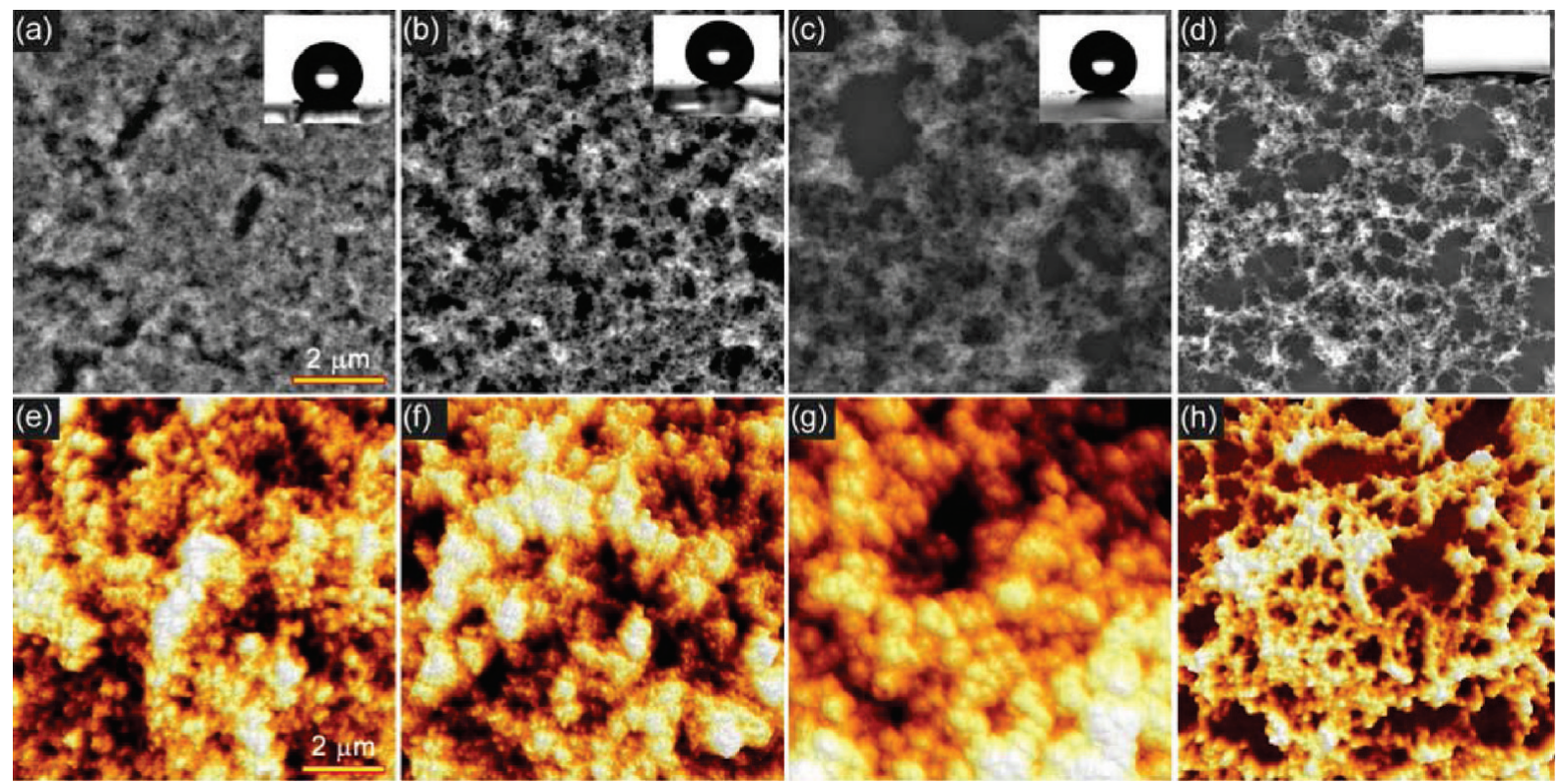

Figure 1. SEM micrographs showing (a) Me15-a, (b) Me25-a, (c) highly porous structure of the uncalcined superhydrophobic Me35-a film, (d) more porous structure of calcined superhydrophilic Me35-c film annealed at $600^{\circ} \mathrm{C}$ for $1 \mathrm{~h}$. Insets show the pictures of water contact angle of corresponding films. AFM images of (e) Me15, (f) Me25-a, (g) Me35-a, and (h) Me35-c are from a $10 \mu \mathrm{m} \times 10 \mu \mathrm{m}$ area.

Combination of micrometer- and nanometer-sized pores provides superhydrophobicity. ORMOSIL aerogel films exhibited very high contact angles reaching $179.9^{\circ}$ (Table 1 ). Combined evaluation of the SEM micrographs and the contact angle measurements revealed that the increase in the macroporosity results in higher static contact angle values. This stems from increasing roughness which allows more air to be trapped between water and surface. We observed that the films were thermally very stable compared to organic coatings. The films preserved the superhydrophobicity even after annealing at $500^{\circ} \mathrm{C}$ for $1 \mathrm{~h}$. For higher temperatures, the contact angle started to decrease and superhydrophilic films with contact angle less than $5^{\circ}$ were obtained at $600{ }^{\circ} \mathrm{C}$ (Figure 1d).

Superhydrophobic coatings must be transparent in order to be used in window glass or solar cells. However, high surface roughness required for superhydrophobicity lowers the transparency by scattering light especially when the roughness is higher than $100 \mathrm{~nm} .{ }^{1,38}$ Thus, the surface roughness must also be optimized to obtain a transparent superhydrophobic coating. The surface roughness of the produced films was determined by the AFM (Figure 1e-h) given in Table 1. Except for Me35-a, which appears translucent, all the other films had average surface roughnesses smaller than $100 \mathrm{~nm}$, resulting in a highly transparent appearance. The TEM image of Me25 dispersion indicated that the suspension was composed of approximately $20-\mathrm{nm}$ sized interconnected ORMOSIL clusters (Figure 2).

Transmittance of Me35 films at different annealing conditions are given in Figure 3a. For comparison, the transmittance of glass substrate is also given. Although as-prepared films have adequate transparency, optical transparency can be further improved by calcination (Figure 3b). It was observed that some calcined films have even higher optical transmission than the glass slide due to reduced back reflections.

Porosity of the films was calculated on the basis of spectroscopic ellipsometric refractive index measurements according to

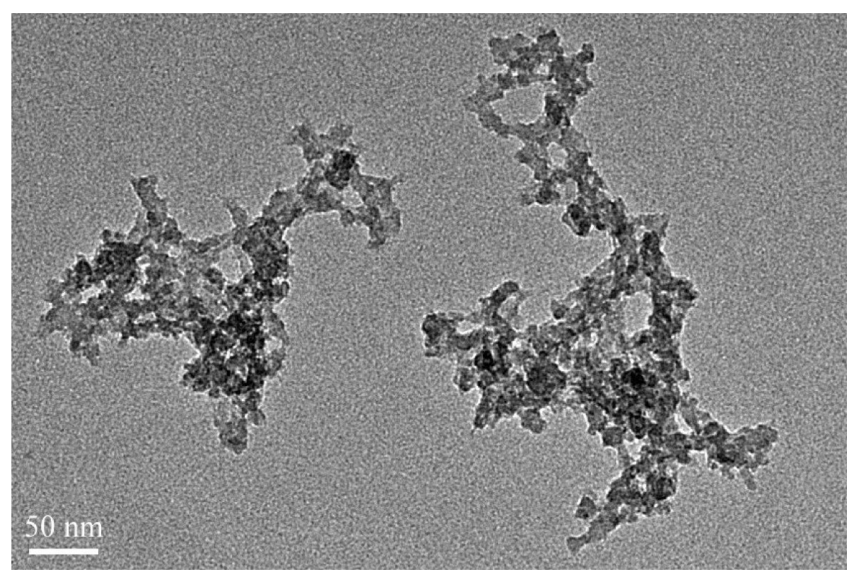

Figure 2. TEM micrograph of Me25 showing the ORMOSIL clusters of approximately $20-\mathrm{nm}$ diameter forming the aerogel network.

the mathematical relationship between the refractive index and porosity as follows: ${ }^{33}$

$$
M=\frac{1.399-n_{\mathrm{D}}}{1.399-n_{\mathrm{A}}}
$$

where 1.399 is the measured refractive index of nonporous film which has been prepared from the same precursor ${ }^{39}$ and $n_{\mathrm{D}}$ and $n_{\mathrm{A}}$ are the refractive indices of the porous film and air. The films were found to have porosities reaching $87.5 \%$. Measured refractive index and calculated porosity values are provided in Table 1 , indicating that closer packing of ORMOSIL clusters for lower methanol mol fractions result in lower porosity, as confirmed by SEM. As a result of lower porosity, these films exhibited higher refractive indices. Calcination results in decrease in the refractive index values for all sets of prepared films, indicating an increase of porosity. For example, refractive index of Me35-a decreases from 1.10 to 1.05 after calcination at $600{ }^{\circ} \mathrm{C}$ for $1 \mathrm{~h}$ (Figure 4). 
(a)

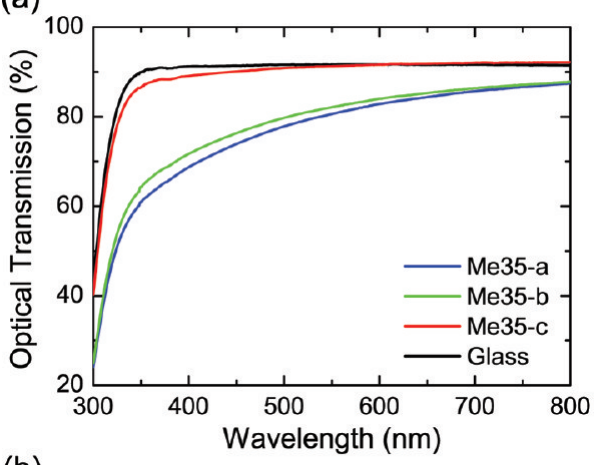

(b)

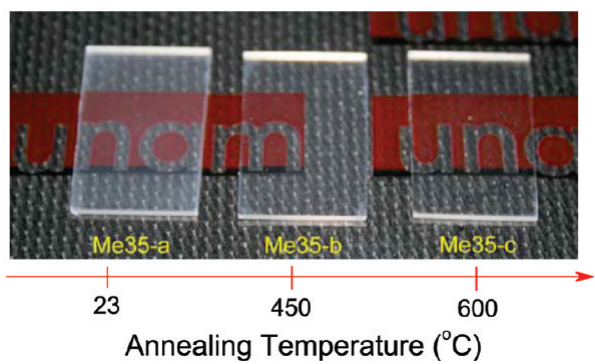

Figure 3. (a) Optical transmission of Me35-a, Me35-b, Me35-c, and plain glass with respect to wavelength. For calcinated thin films at $600{ }^{\circ} \mathrm{C}$ optical transparency is found to be similar to the glass substrates and even better for some wavelengths. (b) Photographs of ORMOSIL aerogel thin films coated on glass substrates. Optical transparency at visible wavelength increases with increasing annealing temperature.

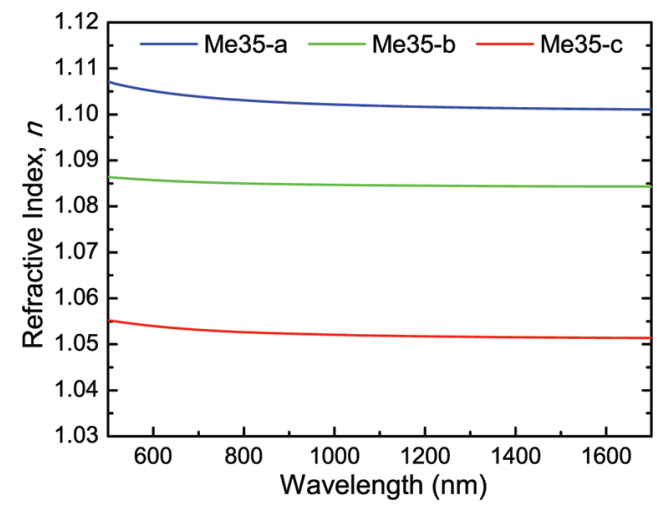

Figure 4. Measured index of refraction of Me35-a, Me35-b, and Me35-c aerogel thin films as a function of wavelength at visible and near-infrared regions. Refractive indices decrease with increasing the annealing temperature.

Enhancement of porosity following calcination was also confirmed by comparison of SEM images obtained from Me35-a and Me35-c films, similar to the affect of chemical composition. Film thicknesses values were also obtained on the basis of ellipsometric measurements and were 550, 800, and $680 \mathrm{~nm}$, respectively, for Me35-a, Me25-a, and Me15-a films.

ORMOSIL suspensions can be applied with common coating techniques like spin, spray, and dip coatings, without requiring any post-treatments. This makes it possible to coat superhydrophobic aerogels on many different surfaces other than glass, including wood, wall tile, aluminum slab, cotton cloth, and plastics, which enables fast and easy production of large-scale
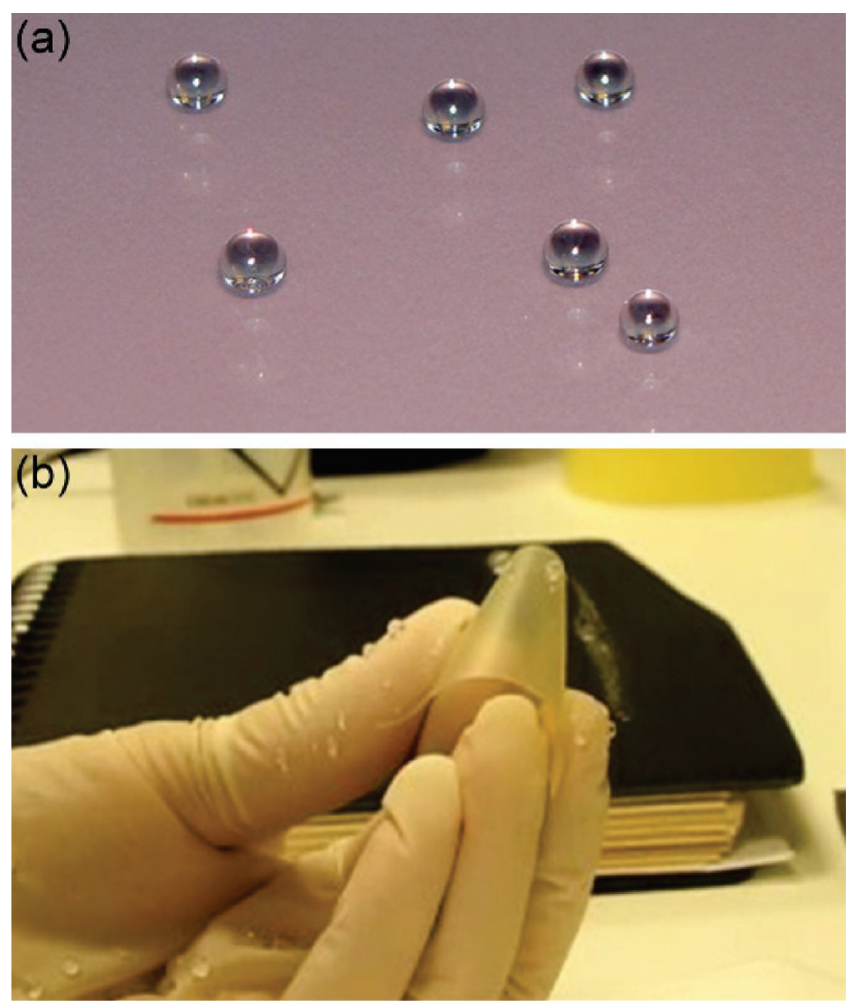

Figure 5. (a) Water droplets on a planar surface coated with Me35-a. (b) Rolling water droplets from superhydrophobic ORMOSIL aerogel thin film coated PES film while it is bent.

Table 2. Static Contact Angles and Sliding Angles of Different Materials after Coating by Me35-a Aerogel Thin Film

\begin{tabular}{lcc}
\multicolumn{1}{c}{ material } & static contact angles $\left({ }^{\circ} \mathrm{C}\right)$ & sliding angles $\left({ }^{\circ} \mathrm{C}\right)$ \\
\hline PEI & $146.1 \pm 2.5$ & 3.1 \\
PES & $156.0 \pm 3.3$ & 3.8 \\
PSU & $156.2 \pm 2.9$ & 2.3 \\
PVDF & $156.7 \pm 3.3$ & 2.3 \\
glass & $178.4 \pm 1.5$ & 0.7 \\
wood & $170.1 \pm 9.7$ & 1.5 \\
wall tile & $167.6 \pm 4.2$ & 2.3 \\
aluminum slab & $172.8 \pm 6.8$ & 2.3 \\
cotton cloth & $157.6 \pm 4.9$ & 3.1 \\
\hline
\end{tabular}

superhydrophobic coatings. The films on flexible substrates exhibit superhydrophobicity even when they are bent, and after many cycles of bending. This indicates that the films themselves are flexible, due to the ORMOSIL network. The static contact angles and sliding angles for Me35-a coated polyetherimide (PEI), polyethersulfone (PES), polysulfone (PSU) (Figure 5), polyvinylidene fluoride (PVDF), a wood surface, wall tile, aluminum slab, and on cotton cloth (Table 2) show that this coating can be successfully applied to obtain different types of flexible superhydrophobic surfaces.

The chemical composition of the Me35-a film was determined on the basis of thermogravimetric analysis (TGA) and differential scanning calorimetry (DSC) measurements and verified with Fourier transform infrared spectroscopy (FTIR). TGA measurement of the Me35-a film (Figure 6a) indicated that calcination of the ORMOSIL network causes some groups to be removed 

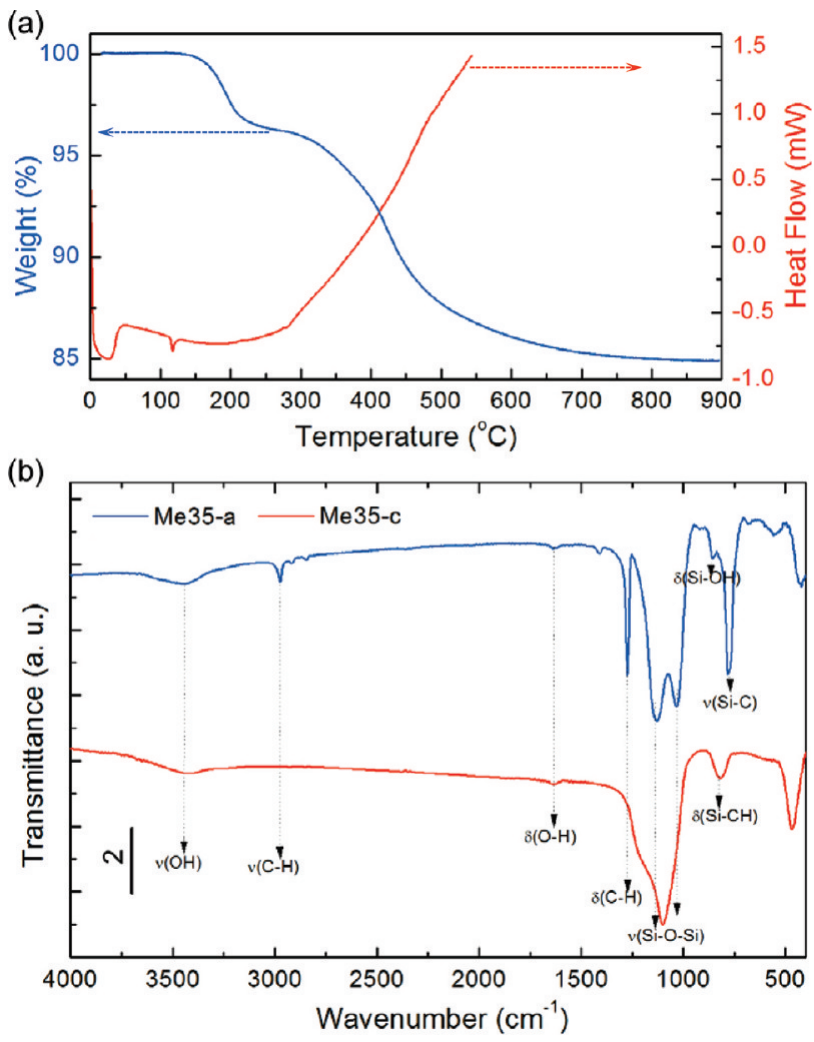

Figure 6. (a) TGA Result of Me35-a film under air flow (blue line) and DSC analysis of the same film (red line) with a temperature ramp of $10{ }^{\circ} \mathrm{C} / \mathrm{min}$ for both analysis. (b) FTIR spectra of Me35-a film indicating incomplete condensation and Me35-c film showing the breaking of methyl groups with annealing. All peaks are assigned according to literature. $^{8}$

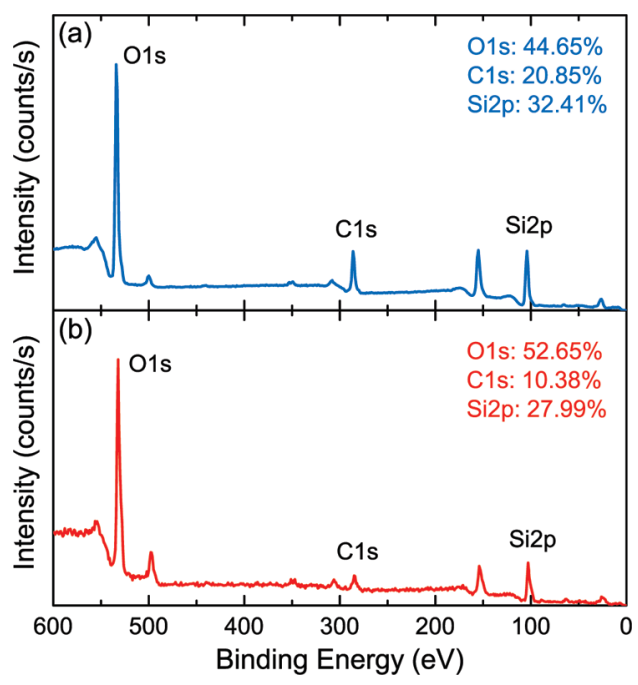

Figure 7. (a) XPS result for uncalcined superhydrophobic aerogel thin film Me35-a. (b) XPS result for calcined superhydrophilic aerogel thin film Me35-c. XPS measurements indicate replacement of surface methyl groups by hydroxyl groups after annealing at $600{ }^{\circ} \mathrm{C}$ for $1 \mathrm{~h}$.

resulting in a decrease of the measured weight. Hydrolysis of MTMS under acidic conditions can yield trisilanol which results in incomplete condensation of silicones with formula $\mathrm{CH}_{3}$ $\mathrm{SiO}_{1.5-n}(\mathrm{OH})_{2 n}{ }^{8}$. The presence of $\mathrm{Si}-\mathrm{OH}$ stretching vibration (a)

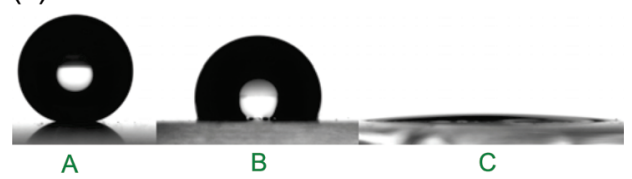

(b)

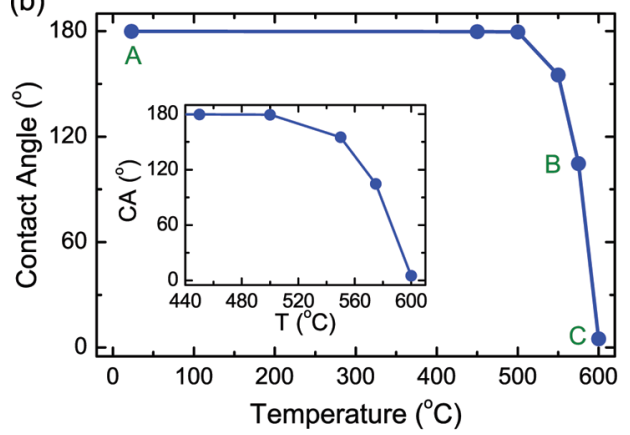

(c)

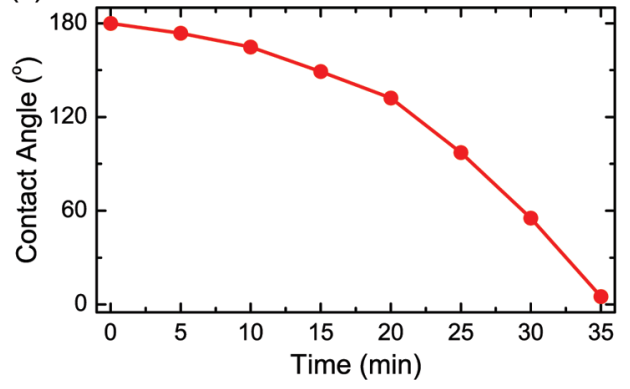

Figure 8. (a) Controlled wettability of water droplet on aerogel thin films calcined at 450,575 , and $600{ }^{\circ} \mathrm{C}$ for $1 \mathrm{~h}$ from left to right. (b) Dependence of contact angle on calcination temperature, for $1 \mathrm{~h}$ durations at each temperature. While the contact angle is nearly unchanged up to $500{ }^{\circ} \mathrm{C}$, it decreases rapidly between 500 and $600{ }^{\circ} \mathrm{C}$. (c) Dependence of contact angle on calcination duration at $600{ }^{\circ} \mathrm{C}$. Contact angle drops continuously as annealing time increases.

around $900 \mathrm{~cm}^{-1}$ observed in the FTIR spectrum (Figure 6b) also verifies incomplete condensation for this sample.

Average weight of the condensation product, $M$, can be calculated from the percentage of solid remaining according to the formula

$$
M=\frac{M_{\mathrm{SiO}_{2}}}{84.9 \%}
$$

where $84.9 \%$ is the percentage of the solid remaining following the calcination up to $900{ }^{\circ} \mathrm{C}$ and $\mathrm{M}_{\mathrm{SiO}_{2}}$ is the molecular weight of $\mathrm{SiO}_{2}$ which is supposed to be the final product. According to eq 2, the chemical formula of the ORMOSIL is found to be $\mathrm{CH}_{3}$ $\mathrm{SiO}_{1.29}(\mathrm{OH})_{0.42}$ and the $n$ value is 0.21 . DSC results given in Figure $6 \mathrm{a}$ also verify the TGA results. At around $300{ }^{\circ} \mathrm{C}$ the weight of the aerogel film started to decrease and simultaneously an exothermic process starts to take place according to DSC result.

The dependence of hydrophobicity on the presence of methyl groups was shown with XPS measurements for Me35-a and Me35-c in Figure 7a and b, respectively. The surface of the ORMOSIL aerogel thin films was composed of oxygen, silicon, carbon, and hydrogen atoms. For Me35-a (Me35-c), oxygen amount was found to be $44.65 \%$ (52.65\%) and carbon amount was found to be $20.85 \%$ (10.38\%). The sharp decrease in the carbon amount and increase in the oxygen demonstrates the replacement of methyl groups with hydroxyl groups upon calcination. 
The decrease in methyl groups was also verified from the FTIR measurements of these samples.

The dependence of contact angle on calcination temperature and duration was investigated in detail using the Me35-a film (Figure 8). In the literature, reported hydrophobic to hydrophilic transition temperatures range from 260 to $480{ }^{\circ} \mathrm{C}$ for the bulk aerogels, ${ }^{27,25,40} 500{ }^{\circ} \mathrm{C}$ for thin films ${ }^{8}$ obtained from same monomer, and $700{ }^{\circ} \mathrm{C}$ for methyltriethoxysilane monomer. ${ }^{21}$ In our study, it was observed that the contact angle of the Me35-a film can be tuned by calcination temperature. Me35-a film was calcined at various temperatures ranging from 450 to $600^{\circ} \mathrm{C}$ for $1 \mathrm{~h}$ periods; conversion from superhydrophobic to superhydrophilic (contact angle $<5^{\circ}$ ) is shown in Figure $8 \mathrm{~b}$. The contact angle vs temperature graph indicates that the contact angle remains constant up to $500{ }^{\circ} \mathrm{C}$ after which it decreases monotonically with increasing temperature. The time dependence of the contact angle on calcination duration at $600{ }^{\circ} \mathrm{C}$ shows the superhydrophilicity is achieved after $35 \mathrm{~min}$ (Figure 8c). These results prove that it is possible to tune wettability of the aerogel thin films by applying appropriate calcination temperature and duration.

\section{CONCLUSIONS}

In this study, a facile method for the preparation of superhydrophobic and highly transparent ORMOSIL aerogel thin films is described. The superhydrophobic ORMOSIL aerogel thin films were prepared from ORMOSIL dispersions in methanol, which were obtained by using an intrinsically hydrophobic organo-silane monomer (MTMS). These ORMOSIL dispersions offer easy handling and good reproducibility for producing superhydrophobic thin films on large areas with simple coating methods. Furthermore, these superhydrophobic films can be applied to almost every substrate without the need of any pretreatments of the substrate. The films on flexible substrates exhibit superhydrophobic behavior even when the substrate is highly bent. This indicates that films are also flexible as a result of the ORMOSIL network.

As-prepared ORMOSIL aerogel thin films have high contact angles (up to $179.9^{\circ}$ ) and low sliding angles $\left(<5^{\circ}\right.$ ), due to two scale roughness. The hydrophobicity of the films is stable up to $500{ }^{\circ} \mathrm{C}$. For higher temperatures, the contact angle value gradually decreases, finally reaching superhydrophilic region $\left(<5^{\circ}\right)$ at $600{ }^{\circ} \mathrm{C}$. As-prepared films are highly transparent (up to $87.6 \%$ at $650 \mathrm{~nm}$ ) and that can be further improved by calcination (up to $92.1 \%$ at $650 \mathrm{~nm}$ ) at high temperatures.

This simple, large area, and low-cost fabrication method of superhydrophobic ORMOSIL aerogel thin films make them suitable as transparent and flexible self-cleaning surfaces for several application fields including solar cells, waterproof textiles, flexible electronics, and lab on papers.

\section{ASSOCIATED CONTENT}

S Supporting Information. Videos showing superhydrophobicity on ORMOSIL thin film coated polymer, aluminum, and ceramic surfaces. This material is available free of charge via the Internet at http://pubs.acs.org.

\section{AUTHOR INFORMATION}

\section{Corresponding Author}

*E-mail: bayindir@nano.org.tr. Phone: +90 312 2903500. Fax: +903122664365.

\section{ACKNOWLEDGMENT}

This work is supported by TUBITAK under the Project 106G090. M.B. acknowledges support from the Turkish Academy of Sciences Distinguished Young Scientist Award (TUBA GEBIP). We thank H. Deniz for TEM images, B. Kaplan, M. K. Abak, B. Daglar, and O. Aktas for AFM measurements, and Dr. M. Yaman for fruitful discussions. This work was performed at UNAM-Institute of Materials Science and Nanotechnology supported by the State Planning Organization of Turkey through the National Nanotechnology Research Center Project.

\section{REFERENCES}

(1) Xu, Q. F.; Wang, J. N.; Sanderson, K. D. ACS Nano 2010, 4, 2201.

(2) Li, X. M.; Reinhoudt, D.; Crego-Calama, M. Chem. Soc. Rev. 2007, 36, 1350.

(3) Gould, P. Mater. Today 2003, 6, 44.

(4) Barkhudarov, P. M.; Shah, P. B.; Watkins, E. B.; Doshi, D. A.; Brinker, C. J.; Majewski, J. Corros. Sci. 2008, 50, 897.

(5) Hikita, M.; Tanaka, K.; Nakamura, T.; Kajiyama, T.; Takahara, A. Langmuir 2005, 21, 7299.

(6) Shang, H. M.; Wang, Y.; Takahashi, K.; Cao, G. Z. J. Mater. Sci. 2005, 40, 3587.

(7) Latthe, S. S.; Imai, H.; Ganesan, V.; Rao, A. V. Microporous Mesoporous Mater. 2010, 130, 115.

(8) Chen, R.; Zhang, X.; Su, Z.; Gong, R.; Ge, X.; Zhang, H.; Wang, C. J. Phys. Chem. C 2009, 113, 8350.

(9) Gao, L.; McCarthy, T. J. J. Am. Chem. Soc. 2006, 128, 9052.

(10) Zhai, L.; Cebeci, F. C.; Cohen, R. E.; Rubner, M. F. Nano Lett. 2004, 4, 1349.

(11) Bravo, J.; Zhai, L.; Wu, Z.; Cohen, R. E.; Rubner, M. F. Langmuir 2007, 23, 7293.

(12) Shi, F.; Chen, X.; Wang, L.; Niu, J.; Yu, J.; Wang, Z.; Zhang, X. Chem. Mater. 2005, 17, 6177.

(13) Liu, X.; He, J. Langmuir 2009, 25, 11822.

(14) Ma, M.; Hill, R. M.; Lowery, J. L.; Fridrikh, S. V.; Rutledge, G. C. Langmuir 2005, 21, 5549.

(15) Zhu, Y.; Zhang, J.; Zheng, Y.; Huang, Z.; Feng, L.; Jiang, L. Adv. Funct. Mater. 2006, 16, 568.

(16) Balu, B.; Breedveld, V.; Hess, D. W. Langmuir 2008, 24, 4785.

(17) Oner, D.; McCarthy, T. J. Langmuir 2000, 16, 7777.

(18) McHale, G.; Aqil, S.; Shirtcliffe, N. J.; Newton, M. I.; Erbil, H. Y. Langmuir 2005, 21, 11053.

(19) He, B.; Patankar, N. A.; Lee, J. Langmuir 2003, 19, 4999.

(20) Pagliaro, M.; Ciriminna, R.; Palmisano, G. J. Mater. Chem. 2009, 19, 3116.

(21) Lim, H. S.; Baek, J. H.; Park, K.; Shin, H. S.; Kim, J.; Cho, J. H. Adv. Mater. 2010, 22, 2138.

(22) Artus, G. R. J.; Jung, S.; Zimmermann, J.; Gautschi, H. P.; Marquardt, K.; Seeger, S. Adv. Mater. 2006, 18, 2758.

(23) Rao, A. V.; Latthe, S. S.; Nadargi, D. Y.; Hirashima, H.; Ganesan, V. J. Colloid Interface Sci. 2009, 332, 484.

(24) Kulkarni, M. M.; Bandyopadhyaya, R.; Sharma, A. J. Mater. Chem. 2008, 18, 1021.

(25) Schirtcliffe, N. J.; McHale, G.; Newton, M. I.; Perry, C. C.; Roach, P. Chem. Commun. 2005, 25, 3135.

(26) Kanamori, K.; Aizawa, M.; Nakanishi, K.; Hanada, T. Adv. Mater. 2007, 19, 1589.

(27) Rao, A. V.; Bhagat, S. D.; Hirashima, H.; Pajonk, G. M. J. Colloid Interface Sci. 2006, 300, 279.

(28) Dong, H.; Reidy, R. F.; Brennan, J. D. Chem. Mater. 2005, 17, 6012.

(29) Prakash, S. S.; Brinker, C. J.; Hurd, A. J.; Rao, S. M. Nature 1995, $374,439$.

(30) Bhagat, S. D.; Oh, C. S.; Kim, Y. H.; Ahn, Y. S.; Yeo, J. G. Microporous Mesoporous Mater. 2007, 100, 350. 
(31) Rao, A. P.; Rao, A. V.; Pajonk, G. M. Appl. Surf. Sci. 2007, 253,6032 .

(32) Bhagat, S. D.; Rao, A. V. Appl. Surf. Sci. 2006, 252, 4289.

(33) Kim, G. S.; Hyun, S. H. Thin Solid Films 2004, 460, 190.

(34) Tsutsui, T.; Yahiro, M.; Yahogawa, H.; Kawano, K.; Yokoyama, M. Adv. Mater. 2001, 13, 1149.

(35) Nishino, T; Meguro, M.; Nakamae, K.; Matsushita, M.; Ueda, Y. Langmuir 1999, 15, 4321.

(36) Miwa, M.; Nakajima, A.; Fujishima, A.; Hashimoto, K.; Watanabe, T. Langmuir 2000, 16, 5754.

(37) Otten, A.; Herminghaus, S. Langmuir 2004, 20, 2405.

(38) Yabu, H.; Shimomura, M. Chem. Mater. 2005, 17, 5231.

(39) Yildirim, A.; Budunoglu, H.; Deniz, H.; Guler, M. O.; Bayindir, M. ACS Appl. Mater. Interfaces 2010, 2, 2892.

(40) Rao, A. V.; Kulkarni, M. M.; Amalnerkar, D. P.; Seth, T. J. Non-Cryst. Sol. 2003, 330, 187. 